\title{
Quantifying the effect of sampling plot size on the estimation of structural indicators in old-growth forest stands
}

\author{
F. Lombardi ${ }^{\text {a,* }}$, M. Marchetti ${ }^{a}$, P. Corona ${ }^{\text {b }}$, P. Merlini ${ }^{\text {b }}$, G. Chirici $^{c}$, R. Tognetti $^{\text {a,d }}{ }^{\text {, S. Burrascano }}{ }^{\text {e }}$, \\ A. Alivernini ${ }^{\text {b }}$, N. Puletti ${ }^{\text {b }}$ \\ ${ }^{a}$ Università del Molise, Dipartimento di Bioscienze e Territorio (DIBT), C.da Fonte Lappone, 86090 Pesche (IS), Italy \\ ${ }^{\mathrm{b}}$ Consiglio per la Ricerca in Agricoltura e l'Analisi dell'Economia Agraria, Forestry Research Centre (CRA-SEL), Viale Santa Margherita 80, 52100 Arezzo, Italy \\ ${ }^{\mathrm{c}}$ Dipartimento di Gestione dei Sistemi Agrari, Alimentari e Forestali - GESAAF, Via San Bonaventura, 1350145 Firenze, Italy \\ ${ }^{\mathrm{d}}$ The EFI Project Centre on Mountain Forests (MOUNTFOR), Edmund Mach Foundation, Via Edmund Mach 1, San Michele all'Adige, 38010, Italy \\ e Sapienza Università di Roma, Dipartimento di Biologia Ambientale (DBA), P.le Aldo Moro 5, 00185 Roma, Italy
}

\section{A R T I C L E I N F O}

\section{Article history:}

Received 14 August 2014

Received in revised form 7 February 2015

Accepted 11 February 2015

Available online 17 March 2015

\section{Keywords:}

Forest structure

Deadwood

Survey simulation

Beech forests

Italy

\begin{abstract}
A B S T R A C T
There is increasing awareness that structure-based indicators should be considered for assessing the biological value of late successional forests. In order to increase the unique habitat features critical for old-growth associated species, it is important to identify and rank candidate potential forest sites on the basis of their distinctive structural features. Data on living and deadwood components for the identification of old-growth condition are usually acquired in the considered forest stands by two sampling survey: (i) census performed in relatively large monitoring sites; (ii) network of small sampling units, on which inventory practices are usually based. Several authors argued that choosing between these survey strategies might have substantial effects on the values of common indicators of old-growth condition. Our study aims at (i) assessing the total estimate differences among old-growth structural indicators measured in field plots with different sizes, and (ii) defining the optimal sample size for the reliable assessment of such indicators. The study was carried out in six beech dominated forest stands on the Apennines range in Italy. In each stand, living and deadwood components were surveyed and geocoded in 1-ha square areas. Based on these dataset, circular plots with radii ranging from $4 \mathrm{~m}$ up to $20 \mathrm{~m}$ were then considered in order to quantify the effect of sampling plot size on the estimation of four structural indicators: (1) number of living trees; (2) number of large trees ( $\mathrm{dbh} \geqslant 50 \mathrm{~cm})$; (3) total deadwood volume; (4) number of deadwood elements (snags, dead standing trees; lying dead trees, lying deadwood) with dbh (or average diameter for lying deadwood) $\geqslant 30 \mathrm{~cm}$. We found that the size of the sampling plots should be at least $500 \mathrm{~m}^{2}$ in order to establish a database for the assessment of the investigated indicators. The census approach should be preferred to the sampling plot approach for old-growth forest stands smaller than 3-5 ha. The achieved results contribute to define assessment protocols for characterizing and ranking the degree to which forest stands approximate old-growth condition based on standardized indicators.
\end{abstract}

(c) 2015 Elsevier B.V. All rights reserved.

\section{Introduction}

Old-growth forests are present in many of the boreal and continental biogeographic regions of Europe and North America (e.g., Wirth et al., 2009). But just a few old-growth forests exist in mountainous Mediterranean contexts, such as the Italian

Abbreviations: VLT, growing stock volume of living trees; NBL, number of large trees; VDE, total volume of dead elements; NBD, number of large dead elements.

* Corresponding author.

E-mail addresses: fabio.lombardi@unimol.it (F. Lombardi), gherardo.chirici@ unifi.it (G. Chirici). peninsula, where forests have been exploited since pre-Roman times (Blondel, 2006). However, since the second half of the 19th century, the socio-economic features in most of the mountainous areas of the Apennines changed rapidly, resulting in extensive abandonment of forest and rural areas, with a significant reduction of human activities and wood exploitation (Saraceno, 1993). As a consequence, many forests have been withdrawn from regular silvicultural management for many years and their structures are now the result of natural processes, i.e. competition, natural development and disturbances (Das, 2012; Lombardi et al., 2008, 2012; Vandekerkhove et al., 2009). 